\title{
Dietary protein intake is associated with maximal and explosive strength of the leg flexors in young and older aged blue collar workers
}

\author{
Brennan J. Thompson ${ }^{a}$, Eric D. Ryan ${ }^{b, c, \bowtie}$, Eric J. Sobolewski ${ }^{a}$, and Abbie E. Smith-Ryan ${ }^{c, d}$ \\ aHuman Performance Laboratory, Department of Health, Exercise and Sport Sciences, Texas \\ Tech University, Lubbock, TX, USA \\ bNeuromuscular Research Laboratory, Department of Exercise and Sport Science, University of \\ North Carolina - Chapel Hill, Chapel Hill, NC, USA \\ ${ }^{\mathrm{c} A l l i e d}$ Health Sciences, University of North Carolina - Chapel Hill Chapel Hill, NC USA \\ ${ }^{\mathrm{d} A p p l i e d}$ Physiology Laboratory, Department of Exercise and Sport Science, University of North \\ Carolina - Chapel Hill, NC USA
}

\begin{abstract}
The aim of this study was to investigate the association between dietary PRO intake and maximal and rapid strength of the leg flexors in blue collar (BC) working men. Twenty-four young (age $=23.2 \pm 2.1 \mathrm{yrs}$ ), and nineteen older aged (age $=52.8 \pm 5.2 \mathrm{yrs}$ ) men employed in BC occupations completed a three day dietary record and isometric strength testing of the leg flexors. Food logs were analyzed for total protein (TPRO) and essential amino acid (EAA) intake. Rapid and maximal strength capacities were examined from the rate of torque development at 50ms (RTD50) and peak torque (PT) of the torque-time curves, respectively. Pearson correlations and partial correlations were used to examine the relationships between TPRO and EAA intake on strength variables. PT was positively correlated to TPRO and EAA intake in the young $(r=0.439$ and $0.431 ; P<0.05)$ and older aged $(r=0.636$ and $0.605 ; P<0.01)$ men and RTD50 was correlated to TPRO and EAA intake in the young $(r=0.512$ and $0.310 ; P=0.01)$ and older aged $(\mathrm{r}=0.662$ and $0.665 ; P<0.01)$ men, respectively. There were no relationships $(P>0.05)$ between TPRO and strength variables when controlling for EAA intake. TPRO intake explained $20-44 \%$ of the variance in rapid and maximal strength for both age groups. EAA intake was largely responsible for the positive relationship between PRO intake and strength. Across young and older aged blue collar working male populations, protein consumption was associated with both maximal and explosive strength capacities of the leg flexors muscle group.
\end{abstract}

(C) 2015 Published by Elsevier Inc.

${ }^{\square}$ Address for Correspondence: Eric D. Ryan, Ph.D., Stallings Fellow Assistant Professor, Neuromuscular Research Laboratory, Department of Exercise and Sport Science, University of North Carolina - Chapel Hill, 209 Fetzer Hall, Campus Box 8700, Chapel Hill, NC 27599-8700, Ph: 919-962-0297, Fax: 919-962-0489, edryan@email.unc.edu.

Publisher's Disclaimer: This is a PDF file of an unedited manuscript that has been accepted for publication. As a service to our customers we are providing this early version of the manuscript. The manuscript will undergo copyediting, typesetting, and review of the resulting proof before it is published in its final citable form. Please note that during the production process errors may be discovered which could affect the content, and all legal disclaimers that apply to the journal pertain.

The authors declare no conflicts of interest 


\section{Key Terms}

Rate of force development; Peak torque; occupation performance; amino acids; essential amino acids; hamstrings

\section{INTRODUCTION}

Despite the modern advances of the information age, occupations comprising blue collar (BC) work still represent the bulk of the labor force, consisting of over $60 \%$ of all occupations [1]. The physical demands and possible associated consequences of injury [2], and early retirement [3] of $\mathrm{BC}$ work yield challenges to the labor force, economy, healthcare system and working individuals. The rapidly shifting demographics of industrialized populations, toward middle and older ages [4], coupled with the reported lack of decline in physical work demands with advancing age $[5,6]$, compound these labor force-related problems. Thus, an improved understanding of individual factors, such as the dietary intake of $\mathrm{BC}$ workers may help facilitate resolutions for improving health and longevity of this large sector of the workforce.

Neuromuscular function is an important element for both health [7] and physical performance [8,9], which are relevant for physically working populations [2]. The functional capacities of the neuromuscular system are most often and appropriately ascertained from outcome measures related to force or torque production characteristics. Typically, maximal strength (often expressed as peak force or peak torque (PT)) has been reported as a means of identifying neuromuscular function, and many previous studies have examined the strength capacities in $\mathrm{BC}$ workers [10-12]. Although maximal strength is an important functional parameter, the ability to rapidly produce force/torque, known as explosive strength or the rate of torque development (RTD), has recently been shown to be a potentially more sensitive muscle function performance variable $[8,9,13]$. For example, previous studies have reported that RTD, but not PT, was able to effectively identify starters from non-starters in Division I NCAA football players [8], Division I NCAA female soccer athletes from college-aged controls [9], and full-time from part-time professional soccer referees [13]. The ability to produce force/torque in a short time period may more effectively represent typical performance tasks, as many common activities require force application response times of less than 200 ms (i.e., balance recovery, jumping, striking) [14]. Although RTD has been examined in several populations, few studies have examined these variables in occupational populations. Moreover, much of the current literature on neuromuscular performance of workers has examined limited muscles of the lower extremities (i.e., leg extensors) [10], or muscles of the upper body (trunk, hand grip strength) [10,11], while investigations have virtually not examined the leg flexors (hamstrings) muscle group.

Given the purported role of dietary protein (PRO) intake for enhancing neuromuscular structure and/or function [15], the potential benefits of optimizing PRO responses on physical function would apply to virtually any population, and in particular for those in which physical performance is a predominant daily attribute. Previous studies have demonstrated that higher dietary PRO intake may be associated with muscle mass and 
function [16-19]. Moreover, it has been shown that essential amino acids (EAA), and in particular leucine, may play a critical role in augmenting protein synthesis [20,21], which may ultimately modulate functional/physiological outcomes [22,23]. We are aware of no studies that have examined the association of dietary PRO and EAA intake on muscle function in $\mathrm{BC}$ working populations. Given the possible link between PRO/EAA dietary consumption and muscle function, an examination of the association between these variables is warranted to aid researchers and practitioners in providing optimal interventional strategies to improve performance and longevity in the $\mathrm{BC}$ working sector. Thus, this study tested the hypothesis that PRO intake in rigorously working adults would be associated with enhanced strength-related muscle function capacities. To test this hypothesis, we conducted a cross-sectional study in young and older aged BC working men, in which we examined the associations between self-reported dietary PRO and EAA intake and maximal and rapid strength capacities of the leg flexors as assessed from isometric maximal voluntary contractions (MVCs).

\section{METHODS AND MATERIALS}

\subsection{Participants}

Twenty-four young (mean \pm SD: age $=23.2 \pm 2.1 \mathrm{yrs}$, height $=174.7 \pm 6.0 \mathrm{~cm}$, body mass $\left.=88.8 \pm 21.0 \mathrm{~kg}, \mathrm{BMI}=29.0 \pm 6.5 \mathrm{~kg} \cdot \mathrm{m}^{2}{ }^{-1}\right)$, and nineteen older aged (age $=52.8 \pm 5.2 \mathrm{yrs}$, height $=175.2 \pm 7.9 \mathrm{~cm}$, weight $=96.5 \pm 15.0, \mathrm{BMI}=31.7 \pm 5.9 \mathrm{~kg} \cdot \mathrm{m}^{2} .-1$ ) men currently employed in $\mathrm{BC}$ occupations volunteered for this investigation. We set the age parameters for the older age group at a minimum of 45 years of age, which is based on the definition of the "older" worker provided by the World Health Organization [24], and the younger age parameter at $<30$ years of age, which are also in line with the age ranges that have been previously defined by investigations comparing younger and older workers [12,25]. The participants were solicited from the local community via advertisements, direct mailings, telephone and in person contact. None of the participants reported any current or ongoing neuromuscular diseases or musculoskeletal injuries of the ankle, knee, or hip of their right leg within one year prior to testing. The study was approved by the University Institutional Review Board and all participants completed and signed a health history questionnaire and informed consent document.

\subsection{Procedures}

The participants visited the laboratory on three separate occasions. For the first session, each participant completed a health history and occupational questionnaire, were provided instructions for completing a three day food log, and then practiced the isometric strength assessments. The participants performed a minimum of three isometric MVCs of the leg flexors on an isokinetic dynamometer. Participants reported back to the laboratory 48-96 hrs following the first visit, for the experimental trial, where they performed the maximal isometric strength testing of the leg flexors. The third visit to the laboratory was to return the food log, which was completed between 6-10 days following the first visit. 


\subsection{Occupational Classification}

All participants in this study were classified as BC workers. Participants met the criteria to be classified as BC workers using a broad classification system based on similar types of occupations similar to the methods of previous studies [26,27]. Specifically, BC occupations were categorized as skilled workers in agricultural, manufacturing, or construction industries, machine installers or operators, assemblers, mechanics, grounds crew and unskilled manual laborers. Occupational information which included work history (months and years in the specified occupation), employment status (full- or part-time), and job task description (type of work tasks commonly performed) was determined from an occupational questionnaire. Each participant's primary occupation was defined as the job that they performed the longest throughout the duration of their occupational life [26], and performed this job for a minimum of $30 \mathrm{hrs}$ per week. To further examine the influence of age, participants were also classified into young (19-28 yrs) or older aged (45-63 yrs) BC groups.

\subsection{Dietary Assessment}

During the initial laboratory visit, detailed verbal instructions were provided to each participant on how to complete a three day dietary record. Specifically, participants were instructed to write down everything they consumed for two non-consecutive days during the week and one weekend day. Guidance notes were provided, in which directions were given detailing the dietary record procedures used to assist participants in describing portion sizes and household measures. Visual illustrations were also provided as a means of aiding in the estimation of portion sizes [28]. The dietary record directions instructed participants to write down all food and drink in the order it was consumed and included all meals, snacks, gum and candy. Participants were instructed to be as specific as possible, including details such as item brand names, as well as the method of food preparation (baked, fried, broiled, etc.). Additionally, all supplements were to be recorded, including the name of the supplement and the amount taken. Dietary intake data were collected and then analyzed by a registered dietician at the Nutrition Obesity Research Center, using Nutrition Data System for Research software version NDSR 2012, developed by the Nutrition Coordinating Center (NCC) at the University of Minneapolis, MN. These data were used to derive total PRO (TPRO), and EAA in grams. Dietary intakes from the three day diet records were averaged. All PRO and amino acid dietary intake amounts ( $\mathrm{g}$ ) were divided by body mass to derive body size relative nutrient intake values, and are based on consumption over a $24 \mathrm{hr}$ period $\left(\mathrm{g} \cdot \mathrm{kg}^{-1} \cdot \mathrm{d}^{-1}\right)$.

\subsection{Isometric Strength Testing}

The MVC testing procedures have been described previously [29]. Briefly, all MVCs were performed using the right leg, on a calibrated Biodex System 4 isokinetic dynamometer (Biodex Medical Systems, Inc. Shirley, NY, USA). For strength testing, participants were seated with restraining straps placed over the trunk, pelvis, and thigh and the lever arm of the dynamometer was strapped to the lower leg via a velcro strap $5 \mathrm{~cm}$ proximal to the lateral malleolus. The input axis of the dynamometer was aligned with the axis of rotation of the knee joint. Prior to the MVCs, participants performed a 5 min warm-up on a cycle 
ergometer at a self-selected low-intensity workload. Following the warm-up, participants performed 2-3 MVCs for the leg flexors at an angle of $60^{\circ}$ below the horizontal plane [8].

\subsection{Signal Processing}

The torque signal was sampled from the dynamometer at $2 \mathrm{KHz}$ with a Biopac data acquisition system (MP150WSW, Biopac Systems, Inc.; Santa Barbara, CA, USA), stored on a personal computer (Dell optiplex, Dell Inc., Round Rock, TX, USA), and processed off-line with custom written software (LabView 8.5, National Instruments, Austin, TX, USA). The raw torque signal was scaled into appropriate units (Newton-meters, $\mathrm{Nm}$ ) and filtered using a fourth order, zero phase shift, low pass Butterworth filter with a $10 \mathrm{~Hz}$ cutoff frequency. The passive baseline torque value was considered the limb weight and subtracted from the signal so that the new baseline value was set at $0 \mathrm{Nm}$. All analyses were performed on the scaled, filtered, and gravity-corrected torque signal.

MVC PT (Nm) was determined as the highest $500 \mathrm{~ms}$ epoch during the entire $4 \mathrm{~s}$ MVC plateau. RTD $\left(\mathrm{Nm} \cdot \mathrm{s}^{-1}\right)$ was calculated from the linear slope of the torque - time curve at 0 $50 \mathrm{~ms}$ (RTD50), similar to the procedures of previous studies [29,30]. This time interval was selected because it has been previously shown that the RTD within the first 50 ms may provide unique physiological information when compared to PT [8,30] or RTD at $200 \mathrm{~ms}$ [31,32]. The onset of contraction was determined as the point when the torque signal reached $4 \mathrm{Nm}$ [29]. The strength-related variables were divided by the participants' body weight in order to provide a body mass normalized expression of maximal (PT) and rapid (RTD50) strength. Reliability statistics for the leg flexor PT and RTD measures based on testing of 10 male participants on two separate occasions separated by $48-72 \mathrm{hrs}$, showed the intraclass correlation coefficients (ICC) and standard error of measurement (SEM) values expressed as a percentage of the mean ranged from $0.82-0.83$ and $6.4-9.0 \%$, respectively [33].

\subsection{Statistical Analyses}

Independent samples $t$-tests were used to examine demographic differences between age groups. Pearson product-moment correlation coefficients $(r)$, and coefficients of determination $\left(r^{2}\right)$ were used to evaluate the relationships between the strength variables (PT and RTD50) and TPRO and EAA intake. Partial correlations were used to examine the relationship between the strength variables (PT and RTD50) and TPRO intake when controlling for EAA intake. SPSS software version 21.0 (SPSS, Inc., Chicago, IL, USA) was used for all statistical analyses and an alpha value of $P \unlhd \emptyset .05$ was considered statistically significant for all comparisons.

\section{RESULTS}

There were no differences between the young and older aged men for height, body mass, or BMI $(P>0.05)$. PT was significantly correlated to RTD50 for both the young $(r=0.512$, $P=0.01)$ and older aged $(r=0.542, P=0.016)$ groups. Data are presented in Table 1 depicting the correlation coefficients between the strength-related (PT and RTD50) and TPRO and EAA variables. PT was correlated to TPRO and EAA intake in the young $(P=0.032$ and 
0.035 , respectively) and older aged $(P<0.01)$ men (Figure 1A). RTD50 was correlated to TPRO and EAA intake in the young $(P=0.011)$ and older aged $(P<0.01)$ men (Figure 1B). The partial correlation coefficients are presented in Table 2. No significant relationships were observed between the strength variables (PT and RTD50) and TPRO intake when controlling for EAA intake for the young $(P=0.617$ and 0.828 for PT and RTD50, respectively) or for the older aged ( $P=0.150$ and 0.913 for PT and RTD50, respectively) men.

\section{DISCUSSION}

The present findings supported the hypothesis, showing that PRO (TPRO and EAA) intake was related to both maximal (PT) and rapid (RTD50) leg flexion strength in young and older aged BC workers. Our findings are in agreement with previous studies that have demonstrated that total dietary PRO intake may be positively associated with maximal muscle strength [19,34,35]. For example, Lemieux et al. [35] found that middle aged and older postmenopausal women who consumed a minimum of $1.2 \mathrm{~g} \cdot \mathrm{kg}^{-1} \cdot \mathrm{d}^{-1}$ of PRO, exhibited 20 and $23.5 \%$ greater leg extension and handgrip strength, respectively, compared to women consuming less than $1.2 \mathrm{~g} \cdot \mathrm{kg}^{-1} \cdot \mathrm{d}^{-1}$ of PRO. In a similar population, Filion et al. [19] reported that dietary PRO had a strong relationship $(r=0.51)$ with hand grip strength, and that those without dynapenia were consuming $37.1 \%$ more daily dietary PRO compared to those with more advanced levels of dynapenia (i.e., type II dynapenic). Furthermore, Benton et al. [34] also reported that PRO intake was positively related to upper $(r=0.61)$ and lower $(r=0.55)$ body 1-repetition maximum (1-RM) strength in elderly men and women with chronic obstructive pulmonary disease. Collectively, these studies indicate that $26-34.8 \%$ of the variance in maximal strength may be explained by total dietary PRO intake, which is relatively similar to the present study for young (19.5\%) and older aged $(40.6 \%)$ BC workers. Although these previous studies have examined the role of TPRO intake in more clinical populations, our findings add additional support to the significant positive relationship between TPRO and EAA intake and maximal muscle strength in healthy, free-living young and older aged rigorously working men.

Because EAA intake has been shown to independently augment muscle protein synthesis [20] and muscle strength gains [22,23], partial correlations were performed to control for EAA intake on the relationships between TPRO intake and PT and RTD50 variables. The partial correlations demonstrated that the relationship between TPRO intake and maximal and rapid strength were no longer significant when controlling for EAA. These results may suggest that the positive relationship between relative TPRO intake and strength is a result of increases in EAA intake, which are likely co-dependent (i.e., EAA intake increases with increases in TPRO intake) [35]. Previous prospective studies provide support for the possible role of EAA intake on eliciting muscle strength gains in glucose impaired elderly [22] and institutionalized [23] populations. However, research is lacking examining the relationship between dietary EAA intake and muscle strength in healthy, young and older aged (45 - 65 yrs) working men. A likely mechanism linking EAA intake to strength increases may be through increases in protein synthesis [20,21], which in theory could improve lean body mass and subsequently enhance force production capacities. In particular, the EAA leucine, appears to play a principal role in muscle protein synthesis; research 
suggests that a critical "threshold" of leucine intake must be reached in order to elicit maximal muscle protein synthesis [36]. In addition, it is possible that other mechanisms connected to PRO and EAA dietary factors, such as insulin-like growth factor-I (IGF-I) mediated enhanced nitrogen balance [37], may also play a role in regulating the expression of muscle strength. However, further research is needed to elucidate the direct influence of EAA intake on muscle strength parameters in young and older aged blue collar working populations as well as the potential role that protein-based dietary nutrients may play in preserving function in even older manual working populations ( $>65 \mathrm{yrs})$.

One novel aspect of the present study was the assessment of rapid strength (RTD), which to our knowledge, is the first to demonstrate that PRO intake was significantly related to RTD. Previous studies which have investigated PRO intake and strength outcomes have almost exclusively made such comparisons using maximal strength (1-RM or PT) as the outcome measure $[19,22,23,34,35]$. Although the present data showed that PT and RTD50 were related, likely suggesting a common basis for their relationships with PRO intake, marginally higher relationships were observed between the RTD50 and PRO/EAA variables compared to that of PT ( 7.5\% more variance was explained for RTD vs EAA than PT vs EAA intake). The expression of rapid strength may be more functionally relevant than maximal strength, as it reflects the capacity of the muscle to produce a rapid rise in force/ torque during more functionally meaningful time periods of less than $200 \mathrm{~ms}$. This is meaningful because many tasks of daily living and occupational performances may require quick response times to avoid injury or to perform important tasks, such as avoiding a fall, being struck by an object, or moving one's body mass or other objects in a time-dependent manner. In addition, rapid strength of the leg flexors (hamstrings muscle group) has been shown to be important for a variety of loco-motor functional movement activities such as running, jumping, agility and balance [9,29,38-40]. For example, a number of previous studies have identified the leg flexors and/or hamstrings as being highly discriminatory of various performances $[8,9,13]$ even when compared with the leg extensors [8]. Collectively, these findings may have important occupational-related implications, especially since novel strategies that incorporate wide-spread practical application are presently being sought to address the critical public health issues concerning the health, longevity, performance, and safety of the aging and increasingly vulnerable working population [41,42]. Accordingly, given these findings show a possible dietary connection with muscle function capacities of the important loco-motor musculature, more research is warranted to extend upon these findings and determine the potential of dietary PRO intake on occupational performance, injury rates, absenteeism, and productivity; as well as to what extent dietary protein characteristics may influence muscle mass specific indices - using sophisticated and sensitive muscle mass measurement techniques (e.g., ultrasound, computed tomography, magnetic resonance imaging) - in blue collar working populations.

The positive association between PRO and EAA intake with muscle function may suggest that increased PRO and EAA intake could serve to benefit muscular performance of young and older aged men employed in physically demanding jobs. Currently, the recommended dietary allowance (RDA) for PRO intake is set at $0.8 \mathrm{~g} \cdot \mathrm{kg}^{-1} \cdot \mathrm{d}^{-1}$ for all adults aged 19 years and older [43], with no additional dietary PRO intake needed for those engaging in resistance or endurance exercise [43]. However, it has been suggested that a higher dietary 
PRO intake requirement of $1.2-1.7 \mathrm{~g} \cdot \mathrm{kg}^{-1} \cdot \mathrm{d}^{-1}$ may be warranted for athletes undergoing exercise training $[44,45]$. Although not athletes in the traditional sense, physically working adults exhibit high activity levels, and the rigorous physical demands of blue collar workers, similar to those in the present study, may qualify such individuals for dietary PRO requirements in excess of the current RDA. For example, PRO intake of the young and older aged men in the present study averaged 1.23 (SD, 0.62; Range, $0.43-3.03)$ and $1.08(0.47$; $0.43-2.38) \mathrm{g} \cdot \mathrm{kg}^{-1} \cdot \mathrm{d}^{-1}$, respectively, with 12 out of the 43 subjects consuming less than the current RDA (i.e. $<0.80 \mathrm{~g} \cdot \mathrm{kg}^{-1} \cdot \mathrm{d}^{-1}$ ). However, we are not aware of any specific PRO intake recommendations for this type of working population. Dietary interventions offer an attractive strategy for addressing the nutritional needs for optimizing performance in the manual working population. Alterations in dietary PRO intake may offer a simple, economical, and wide-spread implementation approach that may readily be incorporated by the large global work force. For example, chronic dietary supplementation of PRO has been reported to be effective in eliciting beneficial changes in muscle function/lean body mass [18]. Furthermore, strategies that incorporate the appropriate timing of PRO intake (i.e. PRO consumption immediately following intense work periods) [15], protein sources (i.e. whey vs soy; animal vs plant) [42,46], and meal-based dosage recommendations $[47,48]$ may be simple strategies to maximize beneficial dietary PRO responses. In light of the present findings, more research is warranted regarding the potential impact of PRO intake on physical function and the role this may have on reducing injury rates and improving performance and productivity in blue collar workers. Accordingly, future research should aim to identify the optimal dietary PRO requirements and intake characteristics for maximal performance and recovery in occupationally demanding physical work conditions. Finally, we acknowledge the potential limitation inherent with self-reported food intake, as these reported intakes may be subject to some reporting error; however, it may be assumed that any error of dietary reporting may be consistent across age-groups. To this point, the similar findings between the two separately analyzed groups would appear to support the validity of these findings.

In summary, the present results revealed a positive relationship for dietary PRO (TPRO and EAA) intake and leg flexor strength (maximal and rapid) in young and older aged blue collar workers. Given the shifting demographics of the labor force towards middle and older ages, coupled with a large increase in the employment of workers past traditional retirement age $[4,49]$, further research is necessary to address the potential role of dietary interventions to match the physical needs of the working individuals that will bear the workload burden. In particular, practical and cost-effective nutritional interventions that optimize/enhance dietary PRO intake characteristics [50] may be an attractive strategy to help improve the health, performance, longevity, and productivity of blue collar workers.

\section{Acknowledgment}

We would like to thank the North Carolina Nutrition Obesity Research Center for performing the food log analyses which is supported by a grant from the NIH (DK056350). The project described was supported by the National Center for Advancing Translational Sciences, National Institutes of Health, through Grant 1KL2TR001109. The content is solely the responsibility of the authors and does not necessarily represent the official views of the NIH. 


\section{Abbreviations}

$\begin{array}{ll}\text { 1-RM } & \text { One Repetition Maximum } \\ \text { BC } & \text { Blue Collar } \\ \text { BMI } & \text { Body Mass Index } \\ \text { EAA } & \text { Essential Amino Acids } \\ \text { IGF-I } & \text { Insulin-like Growth factor-I } \\ \text { MVC } & \text { Maximal Voluntary Contraction } \\ \text { PRO } & \text { Protein } \\ \text { PT } & \text { Peak Torque } \\ \text { RDA } & \text { Recommended Dietary Allowance } \\ \text { RTD } & \text { Rate of Torque Development } \\ \text { RTD50 } & \text { Rate of Torque Development at } 50 \mathrm{~ms} \\ \text { TPRO } & \text { Total Protein }\end{array}$

\section{References}

1. Workers by occupational category 2012. Available from: http://kff.org/other/state-indicator/blueand-white-collar-workers/\#.

2. de Zwart BC, Frings-Dresen MH, van Dijk FJ. Physical workload and the aging worker: a review of the literature. Int Arch Occup Environ Health. 1995; 68:1-12. [PubMed: 8847107]

3. Filer RK, Petri PA. A Job-Characteristics Theory of Retirement. Rev Econ Stat. 1988; 70:123-129.

4. Toossi M. Labor force projections to 2020: a more slowly growing workforce. Mon Labor Rev. 2012 Jan.:43-64.

5. Ilmarinen J. Physical requirements associated with the work of aging workers in the European Union. Experimental aging research. 2002; 28:7-23. [PubMed: 11928212]

6. Nygard CH, Huuhtanen P, Tuomi K, Martikainen R. Perceived work changes between 1981 and 1992 among aging workers in Finland. Scand J Work Environ Health. 1997; 23(Suppl 1):12-19. [PubMed: 9247991]

7. Wolfe RR. The underappreciated role of muscle in health and disease. Am J Clin Nutr. 2006; 84:475-482. [PubMed: 16960159]

8. Thompson BJ, Ryan ED, Sobolewski EJ, Smith DB, Conchola EC, Akehi K, Buckminster T. Can maximal and rapid isometric torque characteristics predict playing level in division I American collegiate football players? J Strength Cond Res. 2013; 27:655-661. [PubMed: 22592169]

9. Palmer TB, Hawkey MJ, Thiele RM, Conchola EC, Adams BM, Akehi K, Smith DB, Thompson BJ. The influence of athletic status on maximal and rapid isometric torque characteristics and postural balance performance in Division I female soccer athletes and non-athlete controls. Clin Physiol Funct Imaging. 2014

10. Era P, Lyyra AL, Viitasalo JT, Heikkinen E. Determinants of isometric muscle strength in men of different ages. Eur J Appl Physiol Occup Physiol. 1992; 64:84-91. [PubMed: 1735418]

11. Nygard CH, Luopajarvi T, Cedercreutz G, Ilmarinen J. Musculoskeletal Capacity of Employees Aged 44-Years to 58-Years in Physical, Mental and Mixed Types of Work. Eur J Appl Physiol Occup Physiol. 1987; 56:555-561. [PubMed: 3653097]

12. Schibye B, Hansen AF, Sogaard K, Christensen H. Aerobic power and muscle strength among young and elderly workers with and without physically demanding work tasks. Appl Ergon. 2001; 32:425-431. [PubMed: 11534787] 
13. Palmer TB, Hawkey MJ, Smith DB, Thompson BJ. The influence of professional status on maximal and rapid isometric torque characteristics in elite soccer referees. J Strength Cond Res. 2014; 28:1310-1318. [PubMed: 24149766]

14. Andersen LL, Andersen JL, Zebis MK, Aagaard P. Early and late rate of force development: differential adaptive responses to resistance training? Scand J Med Sci Sports. 2010; 20:e162e169. [PubMed: 19793220]

15. Cribb PJ, Hayes A. Effects of supplement timing and resistance exercise on skeletal muscle hypertrophy. Med Sci Sports Exerc. 2006; 38:1918-1925. [PubMed: 17095924]

16. Bauer J, Biolo G, Cederholm T, Cesari M, Cruz-Jentoft AJ, Morley JE, Phillips S, Sieber C, Stehle P, Teta D, Visvanathan R, Volpi E, Boirie Y. Evidence-based recommendations for optimal dietary protein intake in older people: a position paper from the PROT-AGE Study Group. Journal of the American Medical Directors Association. 2013; 14:542-559. [PubMed: 23867520]

17. Scott D, Blizzard L, Fell J, Giles G, Jones G. Associations between dietary nutrient intake and muscle mass and strength in community-dwelling older adults: the Tasmanian Older Adult Cohort Study. J Am Geriatr Soc. 2010; 58:2129-2134. [PubMed: 21054294]

18. Cermak NM, Res PT, de Groot LC, Saris WH, van Loon LJ. Protein supplementation augments the adaptive response of skeletal muscle to resistance-type exercise training: a meta-analysis. Am J Clin Nutr. 2012; 96:1454-1464. [PubMed: 23134885]

19. Filion ME, Barbat-Artigas S, Dupontgand S, Fex A, Karelis AD, Aubertin-Leheudre M. Relationship between protein intake and dynapenia in postmenopausal women. J Nutr Health Aging. 2012; 16:616-619. [PubMed: 22836702]

20. Paddon-Jones D, Sheffield-Moore M, Zhang XJ, Volpi E, Wolf SE, Aarsland A, Ferrando AA, Wolfe RR. Amino acid ingestion improves muscle protein synthesis in the young and elderly. Am J Physiol Endocrinol Metab. 2004; 286:E321-E328. [PubMed: 14583440]

21. Volpi E, Kobayashi H, Sheffield-Moore M, Mittendorfer B, Wolfe RR. Essential amino acids are primarily responsible for the amino acid stimulation of muscle protein anabolism in healthy elderly adults. Am J Clin Nutr. 2003; 78:250-258. [PubMed: 12885705]

22. Borsheim E, Bui QU, Tissier S, Kobayashi H, Ferrando AA, Wolfe RR. Effect of amino acid supplementation on muscle mass, strength and physical function in elderly. Clin Nutr. 2008; 27:189-195. [PubMed: 18294740]

23. Rondanelli M, Opizzi A, Antoniello N, Boschi F, Iadarola P, Pasini E, Aquilani R, Dioguardi FS. Effect of essential amino acid supplementation on quality of life, amino acid profile and strength in institutionalized elderly patients. Clin Nutr. 2011; 30:571-577. [PubMed: 21636183]

24. Who Study Group. Aging and working capacity. Geneva, Switzerland: World Health Organization; 1993.

25. Karlqvist L, Leijon O, Harenstam A. Physical demands in working life and individual physical capacity. Eur J Appl Physiol. 2003; 89:536-547. [PubMed: 12728324]

26. Russo A, Onder G, Cesari M, Zamboni V, Barillaro C, Capoluongo E, Pahor M, Bernabei R, Landi F. Lifetime occupation and physical function: a prospective cohort study on persons aged 80 years and older living in a community. Occup Environ Med. 2006; 63:438-442. [PubMed: 16782827]

27. Almoosawi S, Winter J, Prynne CJ, Hardy R, Stephen AM. Daily profiles of energy and nutrient intakes: are eating profiles changing over time? Eur J Clin Nutr. 2012; 66:678-686. [PubMed: 22190135]

28. Seagle HM, Strain GW, Makris A, Reeves RS. Position of the American Dietetic Association: weight management. J Am Diet Assoc. 2009; 109:330-346. [PubMed: 19244669]

29. Thompson BJ, Ryan ED, Sobolewski EJ, Conchola EC, Cramer JT. Age related differences in maximal and rapid torque characteristics of the leg extensors and flexors in young, middle-aged and old men. Exp Gerontol. 2013; 48:277-282. [PubMed: 23142518]

30. Thompson BJ, Ryan ED, Herda TJ, Costa PB, Herda AA, Cramer JT. Age-related changes in the rate of muscle activation and rapid force characteristics. Age. 2014; 36:839-849. [PubMed: 24338233]

31. Palmer TB, Thiele RM, Williams KB, Adams BM, Akehi K, Smith DB, Thompson BJ. The identification of fall history using maximal and rapid isometric torque characteristics of the hip 
extensors in healthy, recreationally active elderly females: a preliminary investigation. Aging Clin Exp Res. 2014

32. Thompson BJ, Stock MS, Shields JE, Luera MJ, Munayer IK, Mota JA, Carrillo EC, Olinghouse KD. Barbell deadlift training increases the rate of torque development and vertical jump performance in novices. J Strength Cond Res. 2015; 29:1-10. [PubMed: 25226322]

33. Weir JP. Quantifying test-retest reliability using the intraclass correlation coefficient and the SEM. J Strength Cond Res. 2005; 19:231-240. [PubMed: 15705040]

34. Benton MJ, Wagner CL, Alexander JL. Relationship Between Body Mass Index, Nutrition, Strength, and Function in Elderly Individuals With Chronic Obstructive Pulmonary Disease. J Cardiopulm Rehabil. 2010; 30:260-263.

35. Lemieux FC, Filion ME, Barbat-Artigas S, Karelis AD, Aubertin-Leheudre M. Relationship between different protein intake recommendations with muscle mass and muscle strength. Climacteric : the journal of the International Menopause Society. 2013

36. Tang JE, Moore DR, Kujbida GW, Tarnopolsky MA, Phillips SM. Ingestion of whey hydrolysate, casein, or soy protein isolate: effects on mixed muscle protein synthesis at rest and following resistance exercise in young men. Journal of applied physiology. 2009; 107:987-992. [PubMed: 19589961]

37. Thissen JP, Ketelslegers JM, Underwood LE. Nutritional regulation of the insulin-like growth factors. Endocrine reviews. 1994; 15:80-101. [PubMed: 8156941]

38. Delecluse C. Influence of strength training on sprint running performance. Current findings and implications for training. Sports Med. 1997; 24:147-156. [PubMed: 9327528]

39. Thompson BJ, Ryan ED, Sobolewski EJ, Smith DB, Akehi K, Conchola EC, Buckminster T. Relationships between rapid isometric torque characteristics and vertical jump performance in division I collegiate american football players: influence of body mass normalization. J Strength Cond Res. 2013; 27:2737-2742. [PubMed: 23302753]

40. Houck J. Muscle activation patterns of selected lower extremity muscles during stepping and cutting tasks. J Electromyogr Kinesiol. 2003; 13:545-554. [PubMed: 14573369]

41. Kirkland K, Dobbin D. Healthy aging for a sustainable workforce: A conference report. Association of Occupational and Environmental Clinics and Society for Occupational and Environmental Health. 2009

42. Farup J, Rahbek SK, Vendelbo MH, Matzon A, Hindhede J, Bejder A, Ringgard S, Vissing K. Whey protein hydrolysate augments tendon and muscle hypertrophy independent of resistance exercise contraction mode. Scand J Med Sci Sports. 2013

43. Institute of Medicine. Dietary Reference Intakes for energy, carbohydrate, fiber, fat, fatty acids, cholesterol, protein, and amino acids. Washington, DC: National Academies Press; 2005.

44. Rodriguez NR, Di Marco NM, Langley S. American College of Sports Medicine position stand. Nutrition and athletic performance. Med Sci Sports Exerc. 2009; 41:709-731. [PubMed: 19225360]

45. Fielding RA, Parkington J. What are the dietary protein requirements of physically active individuals? New evidence on the effects of exercise on protein utilization during post-exercise recovery. Nutrition in clinical care : an official publication of Tufts University. 2002; 5:191-196. [PubMed: 12380246]

46. Phillips SM, Tang JE, Moore DR. The role of milk- and soy-based protein in support of muscle protein synthesis and muscle protein accretion in young and elderly persons. Journal of the American College of Nutrition. 2009; 28:343-354. [PubMed: 20368372]

47. Areta JL, Burke LM, Ross ML, Camera DM, West DW, Broad EM, Jeacocke NA, Moore DR, Stellingwerff T, Phillips SM, Hawley JA, Coffey VG. Timing and distribution of protein ingestion during prolonged recovery from resistance exercise alters myofibrillar protein synthesis. J Physiol. 2013; 591:2319-2331. [PubMed: 23459753]

48. Holwerda AM, van Vliet $S$, Trommelen J. Refining dietary protein recommendations for the athlete. J Physiol. 2013; 591:2967-2968. [PubMed: 23774680]

49. Cote MP, Kenny A, Dussetschleger J, Farr D, Chaurasia A, Cherniack M. Reference values for physical performance measures in the aging working population. Human factors. 2014; 56:228242. [PubMed: 24669556] 
50. Lockwood CM, Moon JR, Tobkin SE, Walter AA, Smith AE, Dalbo VJ, Cramer JT, Stout JR. Minimal nutrition intervention with high-protein/low-carbohydrate and low-fat, nutrient-dense food supplement improves body composition and exercise benefits in overweight adults: A randomized controlled trial. Nutr Metab (Lond). 2008; 5:11. [PubMed: 18426586] 
A

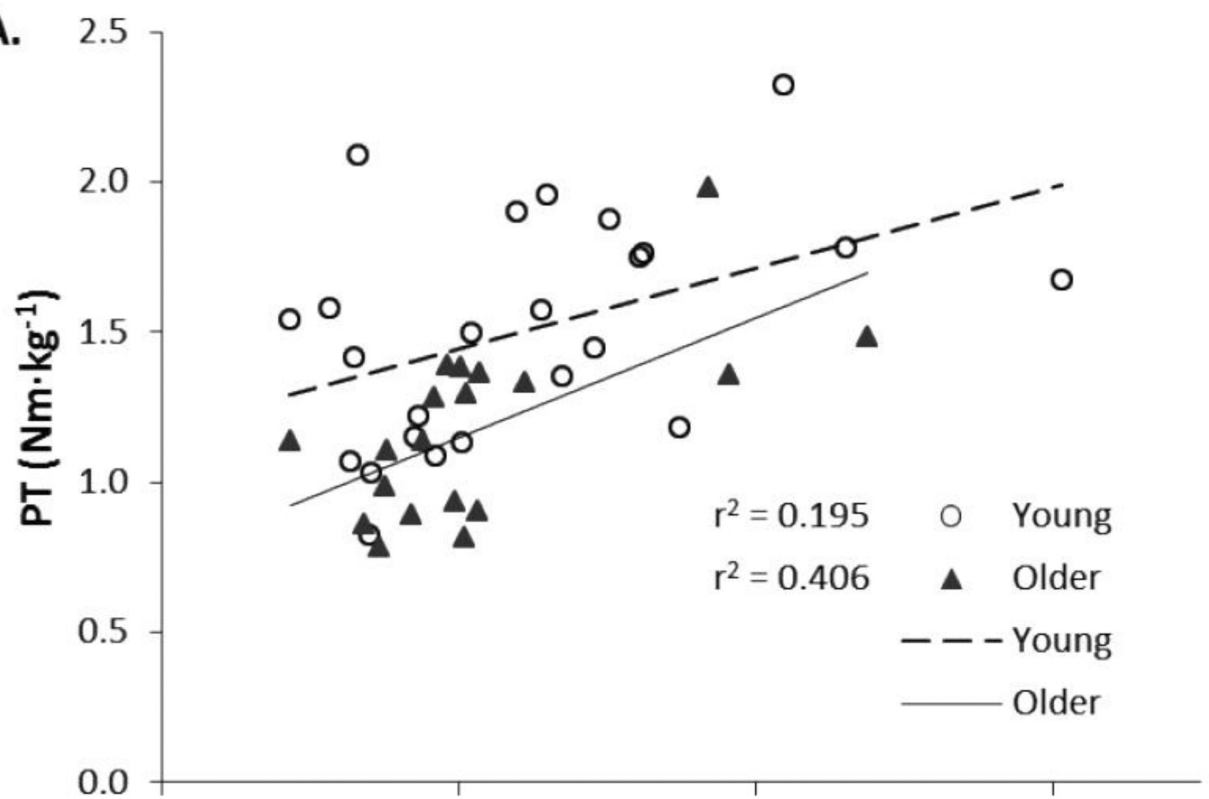

B.

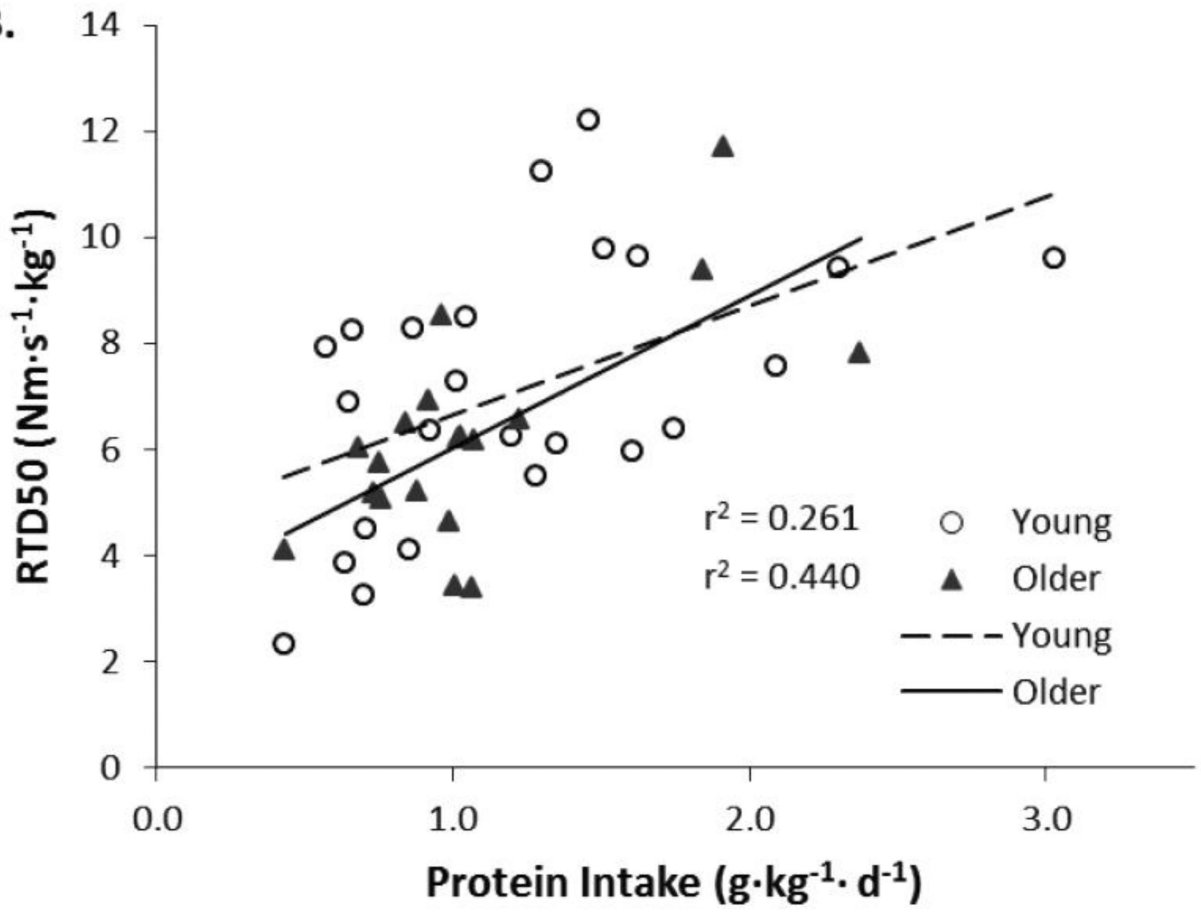

Figure 1.

Pearson product-moment correlations ( $r$ ) between total protein intake and A) peak torque (PT), and B) rate of torque development at $50 \mathrm{~ms}$ (RTD50) in young and older aged men. All relationships were significant at $P \leq 0.05$. 


\section{Table 1}

Relationships between (PT) and (TPRO) and (EAA) intake and (RTD50) and TPRO and EAA intake.

\begin{tabular}{cccc}
\hline & Age Group & TPRO & EAA \\
\hline PT & Young & $0.439^{*}$ & $0.431^{*}$ \\
& Older & $0.636^{*}$ & $0.605^{*}$ \\
\multirow{2}{*}{ RTD50 } & Young & $0.512^{*}$ & $0.510^{*}$ \\
& Older & $0.662^{*}$ & $0.665^{*}$ \\
\hline
\end{tabular}

Values are Pearson product-moment correlation coefficients $(r)$ for the young $(19-28$ yrs; $n=24)$ and older aged $(45-63$ yrs; $n=19)$ blue collar worker groups.

* indicates $P \leq 0.05$;

$\mathrm{PT}=$ Peak Torque, $\mathrm{RTD} 50=$ Rate of Torque Development at $50 \mathrm{~ms}, \mathrm{TPRO}=$ Total Protein, EAA $=$ Essential Amino Acids 
Table 2

Relationships between PT and TPRO intake and RTD50 and TPRO intake in which EAA intake is controlled.

\begin{tabular}{lccc}
\hline & & \multicolumn{2}{c}{$\begin{array}{c}\text { Partial correlation } \\
\text { coefficients with strength } \\
\text { variables }\end{array}$} \\
\cline { 3 - 4 } & $\begin{array}{c}\text { Control } \\
\text { Variable }\end{array}$ & Young & Older \\
\hline PT & EAA & 0.11 & 0.354 \\
RTD50 & EAA & 0.048 & 0.028 \\
\hline
\end{tabular}

Values are partial correlation coefficients $(r)$ for the young $(19-28 \mathrm{yrs} ; \mathrm{n}=24)$ and older aged $(45-63 \mathrm{yrs} ; \mathrm{n}=19)$ blue collar worker groups.

$\mathrm{PT}=$ Peak Torque RTD50 $=$ Rate of Torque Development at $50 \mathrm{~ms} ;$ TPRO $=$ Total Protein $;$ EAA $=$ Essential Amino Acids 